\title{
A retrospective study of obstetric hysterectomy cases at tertiary care centre
}

\author{
Khushi P. Joshi*, Sapana R. Shah, Saumya P. Agrawal, Vishwa Goswami
}

Department of Obstetrics and Gynecology, Smt. NHL Municipal Medical College, SVPIMSR, Ahmedabad, Gujarat, India

Received: 08 May 2020

Accepted: 01 June 2020

*Correspondence:

Dr. Khushi P. Joshi,

E-mail: jkp14194@gmail.com

Copyright: () the author(s), publisher and licensee Medip Academy. This is an open-access article distributed under the terms of the Creative Commons Attribution Non-Commercial License, which permits unrestricted non-commercial use, distribution, and reproduction in any medium, provided the original work is properly cited.

\begin{abstract}
Background: Postpartum haemorrhage (PPH) is a life-threatening condition. The objective of this study was to determine the incidence, demographic characteristics, indications, and feto-maternal outcomes associated with obstetric hysterectomy in a tertiary care centre.

Methods: This is a retrospective analytical study conducted over a period of six years, from March 2014 to April 2020. A total of 68 cases of obstetric hysterectomy were studied at tertiary care centre in Ahmedabad, Gujarat, India.

Results: Present study reported 68 obstetric hysterectomies per 44663 total deliveries (incidence - $0.15 \%$ ), out of them 20 following 26446 vaginal deliveries $(0.07 \%)$ and 48 following 18217 caesarean section $(0.26 \%)$. Morbidly adherent placenta $(29.41 \%)$ was the most common indication followed by atonic postpartum haemorrhage $(25.00 \%)$ and uterine rupture $(17.64 \%)$. The most frequent sequelae were disseminated intravascular coagulation $(26.47 \%)$ and febrile morbidity $(10.29 \%)$, maternal mortality was $16.17 \%$ whereas neonatal mortality was $26.47 \%$.

Conclusions: The incidence of obstetric hysterectomy has been found to be more following caesarean sections. There is a change in the indications of obstetric hysterectomy in the past two decades with placenta accreta spectrum being the commonest in present study. This is because of rising number of caesarean sections. Patients who underwent emergency obstetric hysterectomy due to atonic PPH had a higher mortality.
\end{abstract}

Keywords: Maternal mortality, Morbidly adherent placenta, Obstetric hysterectomy, Postpartum haemorrhage

\section{INTRODUCTION}

Postpartum haemorrhage (PPH) is a life-threatening condition. Various drugs and surgical techniques have been developed over time, especially to preserve the uterus. An emergency obstetric hysterectomy has to be performed often as the last resort in saving a woman's life. It is thus an unequivocal marker of severe maternal morbidity and mortality.

Obstetric hysterectomy $(\mathrm{OH})$ is defined as extirpation of the uterus either at the time of caesarean section or following vaginal delivery, or within the puerperium period. It is usually performed in the face of unrelenting and life-threatening obstetric haemorrhage. A near miss event is defined as "a woman who nearly died but survived a complication that occurred during pregnancy, childbirth, or within 42 days of termination of pregnancy". ${ }^{1} \mathrm{OH}$ can be rightly classified as a near miss event. It is important to study such events since they provide an insight into the standard of care provided and help to reduce maternal morbidity and mortality. In case of morbidly adherent placenta, a preterm elective caesarean hysterectomy has to be planned.

\section{METHODS}

This is a retrospective, analytical study of 68 parturient women requiring obstetric hysterectomy $(\mathrm{OH})$. The study is conducted over a six-year period, from March 2014 to 
April 2020 in the department of obstetrics and gynecology at tertiary care centre.

\section{Inclusion criteria}

- All the women who delivered after 24 weeks of gestation in the hospital and all women who delivered outside the hospital and were referred for obstetric complications who underwent obstetric hysterectomy were included in the study.

\section{Exclusion criteria}

- Women who delivered before 24 weeks of gestation, undergoing hysterectomy for indications other than obstetric were excluded from the study.

A detailed analysis of condition of patient, indication for obstetrics hysterectomy, intraoperative and post-operative complication was made using data from indoor sheet, treatment chart, operation theatre record, operation notes, delivery record, maternal mortality record. Relevant data were extracted and analysed using predesigned form.

\section{RESULTS}

Out of 44663 deliveries, the incidence of obstetric hysterectomy in this study was $0.07 \%$ following vaginal delivery (20 following 26446 vaginal deliveries) and
$0.26 \%$ following caesarean section (48 following 18217 caesarean section). The overall incidence was $0.15 \%$ (68 obstetric hysterectomies per 44663 total deliveries) (Figure 1).

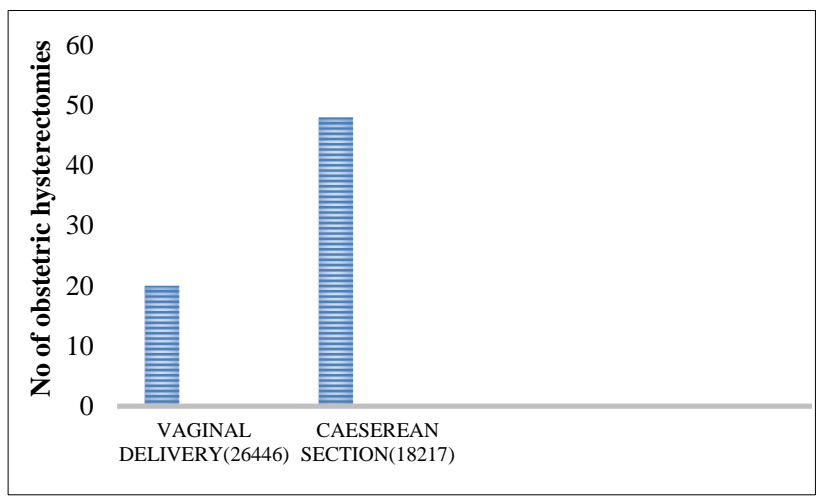

Figure 1: Incidence of obstetric hysterectomies (OH) following vaginal delivery and caesarean section.

Women in the 20 to 30 -year-old age group constituted $70.58 \%$ of cases, and $79.40 \%$ of cases were multiparous (Table 1).

The most common indication of $\mathrm{OH}$ in this study was morbidly adherent placenta $(29.41 \%)$ followed by uterine atony $(25.00 \%)$ and uterine rupture (18.46\%) (Table 2).

Table 1: Maternal characteristics in present study (age and parity).

\begin{tabular}{|lllllll|}
\hline Age $($ years $)$ & Parity=1 & Parity=2 & Parity=3 & Parity=4 & Parity $>=5$ & Total \\
\hline $20-25$ & 8 & 9 & 3 & 0 & 0 & $20(29.41 \%)$ \\
\hline $25-30$ & 4 & 5 & 16 & 2 & 0 & $28(41.17 \%)$ \\
\hline $30-35$ & 2 & 4 & 5 & 1 & 2 & $14(20.58 \%)$ \\
\hline $35-40$ & 0 & 0 & 2 & 4 & 1 & $6(8.82 \%)$ \\
\hline Total & $14(20.59 \%)$ & $18(26.47 \%)$ & $26(38.23 \%)$ & $7(10.29 \%)$ & $3(4.41 \%)$ & $68(100 \%)$ \\
\hline
\end{tabular}

Table 2: Indications of emergency obstetric hysterectomy in the study population.

\begin{tabular}{|ll|}
\hline Indications & N $(\%)$ \\
\hline Morbidly adherent placenta & $20(29.41 \%)$ \\
\hline Atonic postpartum haemorrhage & $17(25.00 \%)$ \\
\hline Uterine rupture & $12(17.64 \%)$ \\
\hline Abruptio placentae & $10(14.70 \%)$ \\
\hline Placenta praevia & $8(11.76 \%)$ \\
\hline Broad ligament haematoma & $1(1.47 \%)$ \\
\hline Total & $68(100 \%)$ \\
\hline
\end{tabular}

All cases of morbidly adherent placenta were associated with history of previous one or more caesarean sections. Out of 12 cases of uterine rupture 8 cases $(66.66 \%)$ were associated with previous caesarean, 2 cases $(16.66 \%)$ with multiparty, 1 case $(8.3 \%)$ of obstructed labour and 1 case $(8.3 \%)$ with multifetal gestation.

Out of the 17 cases who underwent $\mathrm{OH}$ for Atonic postpartum haemorrhage 11 cases $(64.70 \%)$ found to be occur following vaginal delivery and 6 cases $(35.29 \%)$ found to be occur following caesarean section. Of the cases who underwent $\mathrm{OH}$, stepwise devascularisation including bilateral uterine and ovarian artery ligation was performed in 16 cases $(23.52 \%)$.

Uterine packing or tamponade was employed in 13 cases $(19.11 \%)$ and vaginal or paraurethral tears were stitched in 8 cases $(11.76 \%)$.

Hospital stay ranged from 6 days to 28 days. ICU stay ranged from 1 to 6 days. 
Almost $41.17 \%$ (28 cases) required ICU admission, $29.41 \%$ (20 cases) of patients needed vasopressors such as dopamine, dobutamine, noradrenaline infusion and vasopressin as and when needed as per description of the anaesthetist. Coagulopathy occurred in $26.47 \%$ (18 cases) and febrile morbidity occurred in $10.29 \%$ ( 7 cases). Nearly $41.17 \%$ (28 cases) of neonates were admitted to neonatal intensive care unit (NICU). Neonatal mortality in this study was $26.47 \%$ (18 cases).

Patients received transfusion of blood and blood products, as per requirement, ranging from 3 to 26 units, with an average of 8 units.

Table 3 shows the incidence of feto-maternal complications.

Table 3: Feto-maternal complications after OH $(n=68)$.

\begin{tabular}{|ll|}
\hline Maternal & N $(\%)$ \\
\hline Fever & $7(10.29 \%)$ \\
\hline Coagulopathy & $18(26.47 \%)$ \\
\hline Wound sepsis & $6(8.82 \%)$ \\
\hline Need for vasopressors & $20(29.41 \%)$ \\
\hline ICU admission & $28(41.17 \%)$ \\
\hline Mortality & $11(16.17 \%)$ \\
\hline Relaparotomy & $0(0 \%)$ \\
\hline Fetal & \\
\hline++ & $28(41.17 \%)$ \\
\hline NICU admission & $18(26.47 \%)$ \\
\hline Mortality &
\end{tabular}

\section{DISCUSSION}

Obstetric hysterectomy is a technically challenging procedure due to the anatomic and physiologic changes of pregnancy, including a massive increase in blood flow to the uterus at term. The surgery is frequently performed in emergent, unplanned situations when a mother's life is in danger and it permanently ends future fertility. Obstetric hysterectomy is becoming more common largely due to the rising primary caesarean delivery rate.

In present study, majority of patients who underwent $\mathrm{OH}$ were in age group 20-30 years and were multipara. Majority $(41.4 \%)$ of the women were of 25-30 years of age showing more obstetric hysterectomies at peak of obstetric career. This is comparable to other study Sheikh $\mathrm{N}$ et al. ${ }^{2}$ However a study observed by Amad and Mir and Barclay et al reported that majority of patients who underwent $\mathrm{OH}$ were in age group $\geq 35$ years and were multipara. ${ }^{3,4}$

The most common indication of $\mathrm{OH}$ in this study was morbidly adherent placenta $(29.41 \%)$ followed by uterine atony $(25.00 \%)$ and uterine rupture $(17.64 \%)$. Stanco et al, reported that $43.4 \%$ of their emergency hysterectomies were done because of uterine atony, while $33.9 \%$ were due to placenta previa with accreta. A study from the same institution in 1993 stated that their primary indication was placenta accreta, the problem in $45 \%$ of cases, followed by uterine atony, with $20 \% .^{5}$

A very important observation is the prominent association of prior caesarean delivery with the three major indications of $\mathrm{OH}$. History of prior caesarean section was associated with atony in $41.6 \%$ of cases, with morbidly adherent placenta in $65 \%$ of cases, and with uterine rupture in $63.70 \%$ of cases. It may be prudent to emphasize here that morbidly adherent placenta was associated with a previous caesarean section in $28 \%$ of cases and with two previous caesareans in $34 \%$ of cases, $3 \%$ with more than two previous sections. Kastner et al, analysed 47 cases from 1991 to 1997, with placenta accrete accounting for $48.9 \%$ of the cases; $51.1 \%$ of the women in their study had had a previous caesarean delivery. ${ }^{6}$ Zelop et al, analysed adherent placentation accounting for $64 \%$ of the cases; $59.8 \%$ had a previous caesarean delivery. ${ }^{7}$ The incidence of obstetric hysterectomy is increasing in this era not because of improperly managed third stage of labour or obstructed labour but most likely because of increasing incidence of caesarean sections. Chances of repeat caesarean sections thus increase. This ultimately increases the incidence of placenta previa and accrete. In recent studies, the incidence of obstetric hysterectomy was higher in women who had a history of either one or two previous caesarean sections. Placenta accreta has been the primary indication in these women and accounts for $38 \%-50 \%$ of all obstetric hysterectomies. ${ }^{8-12}$ Bateman et al, also found that the rate of $\mathrm{OH}$ for atony increased 4-fold following repeat caesarean section, 2.5-fold following primary caesarean section, and 1.5 -fold following primary vaginal delivery over a period of 14 years. ${ }^{13}$

A total of $17.64 \%$ of cases underwent hysterectomy for uterine rupture, $63.7 \%$ of these had a scarred uterus. Uterine rupture leads to $\mathrm{EOH}$ in $8 \%$ of cases in the UK, and close to $17 \%$ in Turkey. ${ }^{14}$ Korejo et al, from Pakistan, recently reported that $47.1 \%$ of cases were the result of uterine rupture. ${ }^{15}$ Of all the cases of uterine rupture, $26 \%$ had scarred uterus. $15 \%$ of atony cases and $8.3 \%$ of uterine rupture cases were associated with multiple gestation in this study. A study from the US concluded that higher-order births are associated with a 24-fold increase in the incidence of emergency hysterectomy. Uterine distension, use of tocolysis to avert preterm labour, and placental causes have been postulated to be responsible for this increase. ${ }^{16}$ Walker et al, from Canada have also reported a similar association. ${ }^{17}$ However, a study by Bodelon et al, did not find a positive correlation. ${ }^{18}$ The incidence of uterine rupture as an indication for obstetric hysterectomy has significantly reduced which may be attributed to decreased referrals of women with obstructed labour.

In this study, there were 11 maternal deaths (16.17\%). All of these women were referred from outside, and the cause 
of death was atonic PPH. In previous studies, also, the maternal mortality ranges from $1.2 \%$ to $19.4 \% .{ }^{19}$ Although the incidence of atonic PPH as an indication of obstetric hysterectomy has reduced, it is still important and was the only cause of maternal deaths in this study.

Maternal mortality in this series is towards the higher end of the range when compared to other countries. The figures from different parts of the world range from $7 \%$ to $17 \%$. Authors reported a slightly higher value of $16.17 \%$. This could probably be explained by the fact that many other studies from single centers have fewer total deliveries per year. Authors have reported from a pool of 44663 child births.

\section{CONCLUSION}

Abnormal adherent placentation is replacing uterine atony as the most common indication for emergency obstetric hysterectomy. History of caesarean section reported increased incidence of obstetric hysterectomy in women with high-risk pregnancy, due to its relation to placentation disorders such as morbidly adherent placenta that increases haemorrhage possibility, and thus, maternal morbidity and mortality. Rising rates of caesarean section and multiple pregnancies are bound to increase the incidence of $\mathrm{EOH}$ in the future.

Funding: No funding sources

Conflict of interest: None declared

Ethical approval: The study was approved by the Institutional Ethics Committee

\section{REFERENCES}

1. Say L, Souza JP, Pattinson RC. WHO working group on maternal mortality and morbidity classifications. Maternal near mis-towards a standard tool for monitoring quality of maternal health care. Best Pract Res Clin Obstet Gynaecol. 2009;23(3):287-96.

2. Shaikh N, Shaikh S, Shaikh J. Morbidity and mortality associated with obstetric hysterectomy. J Ayub Med Coll Abbottabad. 2010;22(2):100-1.

3. Amad SN, Mir IH. Emergency peripartum hysterectomy: experience at Apex Hospital of Kashmir Valley. Internet J Gynecol Obstet. 2007;8:2.

4. Barclay DL, Hawks BL, Frueh DM. Elective cesarean hysterectomy: a 5-year comparison with cesarean section. Am J Obstet Gynecol. 1976;124(8):900-11.

5. Stanco LM, Schrimmer DB, Paul RH, Mishell DR. Emergency peripartum hysterectomy and associated risk factors. Am J Obstet Gynecol. 1993;168(3):87983.
6. Kastner ES, Fifueroa R, Garry D, Maulik D. Emergency peripartum hysterectomy: experience at a community teaching hospital. Obstet Gynecol. 2002;99:9715.

7. Zelop CM, Harlow BL, Frigoletto FD, Safon LE, Saltzman DH. Emergency peripartum hysterectomy. Am J Obstet Gynecol. 1993;168:14438.

8. Agrawal S, Yadav R, Raghunandan C, Dhingra S, Kaur H. Peripartum hysterectomy in a teaching hospital in India. Asian J Med Sci. 2013;4:5-9.

9. Korejo R, Nasir A, Yasmin H, Bhutta S. Emergency obstetric hysterectomy. J Pak Med Assoc. 2012;62:1322-5.

10. Kastner ES, Figueroa R, Garry D, Maulik D. Emergency peripartum hysterectomy: Experience at a community teaching hospital. Obstet Gynecol. 2002;99:971-5.

11. Kwee A, Bots ML, Visser GH, Bruinse HW. Emergency peripartum hysterectomy: a prospective study in the Netherlands. Eur J Obstet Gynecol Reprod Biol. 2006;124:187-92.

12. Sakse A, Weber T, Nickelsen C, Secher NJ. Peripartum hysterectomy in Denmark 1995-2004. Acta Obstet Gynecol Scand. 2007;86:1472-5.

13. Bateman BT, Mhyre JM, Callaghan WM, Kuklina EV. Peripartum hysterectomy in the United States: nationwide 14-year experience. Am J Obstet Gynecol. 2012;206(1):63.e1-63.e8.

14. Knight M, UKOSS . Peripartum hysterectomy in the UK: management and outcomes of the associated haemorrhage. BJOG. 2007;114(11):1380-7.

15. Korejo R, Nasir A, Yasmin H, Bhutta S. Emergency obstetric hysterectomy. J Pak Med Assoc. 2012.;62(12):1322-5.

16. Francois K, Ortiz J, Harris C, Foley MR, Elliott JP. Is peripartum hysterectomy more common in multiple gestations? Obstet Gynecol. 2005.;105(6):1369-72.

17. Walker MC, Murphy KE, Pan S, Yang Q, Wen SW. Adverse maternal outcomes in multifetal pregnancies. An Int J Obstet Gynaecol. 2004;111:1294-6.

18. Bodelon C, Bernabe-Ortiz A, Schiff MA, Reed SD. Factors associated with peripartum hysterectomy. Obstet Gynecol 2009. Jul;114(1):115-123. 10.1097/AOG.0b013e3181a81cdd

19. Say L, Chou D, Gemmill A, Tunçalp Ö, Moller AB, Daniels J, et al. Global causes of maternal death: a WHO systematic analysis. Lancet Glob Health. 2014;2(6):e323-33.

Cite this article as: Joshi KP, Shah SR, Agrawal SP, Goswami V. A retrospective study of obstetric hysterectomy cases at tertiary care centre. Int $\mathbf{J}$ Reprod Contracept Obstet Gynecol 2020;9:2813-6. 